Published in final edited form as:

Eur J Pharmacol. 2007 September 24; 571(1): 39-43.

\title{
The cannabinoid $\mathrm{CB}_{1}$ receptor antagonist $\mathrm{AM} 251$ does not modify methamphetamine reinstatement of responding
}

\author{
Sherin Y. Boctor ${ }^{1}$, Joe L. Martinez Jr. ${ }^{1}$, Wouter Koek ${ }^{2}$, and Charles P. France ${ }^{2}$ \\ 1 Cajal Neuroscience Institute, Department of Biology, University of Texas at San Antonio, San Antonio, Texas \\ 78249, USA \\ 2Departments of Pharmacology and Psychiatry, University of Texas Health Science Center at San Antonio, \\ San Antonio, Texas 78229, USA
}

\begin{abstract}
Cannabinoid $\mathrm{CB}_{1}$ receptor antagonists can decrease methamphetamine self administration. This study examined whether the $\mathrm{CB}_{1}$ receptor antagonist AM251 [N-(piperidin-1-yl)-5-(4indophonyl)-1-(2,4-dichlorophenyl)-4-methyl-1H-pyrazole-3-carboxamide] modifies reinstatement in rats that previously self-administered methamphetamine. Rats $(\mathrm{n}=10)$ self administered methamphetamine $(0.1 \mathrm{mg} / \mathrm{kg} /$ infusion $)$ under a fixed ratio 2 schedule. Non-contingent methamphetamine $(0.01-1.78 \mathrm{mg} / \mathrm{kg}$, i.v.) yielded responding for saline (reinstatement) that was similar to responding for self-administered methamphetamine. AM251 (0.032-0.32, i.v.) did not affect methamphetamine-induced reinstatement but significantly attenuated $\Delta^{9}$ tetrahydrocannabinol $(2.0 \mathrm{mg} / \mathrm{kg}$, i.p.)-induced hypothermia. These data fail to support a role for endogenous cannabinoids or cannabinoid $\mathrm{CB}_{1}$ receptors in reinstatement and, therefore, relapse to stimulant abuse.
\end{abstract}

\section{Keywords}

cannabinoid receptor; methamphetamine; AM251; reinstatement; self administration; rat

\section{Introduction}

Methamphetamine $\left(\right.$ Desoxyn $\left.{ }^{\circledR}\right)$ is used clinically to treat narcolepsy, attention deficit disorder, and obesity (Bray, 1993; Greenhill, 2006). However, the therapeutic utility of stimulants is limited due to their high abuse potential (Kroutil et al., 2006). For example, recreational use of methamphetamine has increased dramatically with an estimated 12 million Americans (4.9\% of those 12 years and older) having used methamphetamine (SAMHSA, 2005).

Worldwide marijuana is the most widely-used illicit drug with an estimated 96.8 million Americans (40.2\% of those 12 years and older) having used marijuana (National Survey of Drug Use and Health: Population Estimate 2004). Marijuana, like methamphetamine, can increase dopamine neuronal firing and inhibit dopamine reuptake, thereby increasing extracellular concentrations of dopamine (e.g., Gardner, 2005) which is believed to be important for the abuse-related effects of these and other drugs. $\Delta^{9}$-Tetrahydrocannabiol (THC)

Correspondence to: Charles P. France, Department of Pharmacology, University of Texas Health Science Center, 7703 Floyd Curl Drive, San Antonio, TX 78229, USA, 2105676969,2105670104 (fax), france@ uthscsa.edu.

Publisher's Disclaimer: This is a PDF file of an unedited manuscript that has been accepted for publication. As a service to our customers we are providing this early version of the manuscript. The manuscript will undergo copyediting, typesetting, and review of the resulting proof before it is published in its final citable form. Please note that during the production process errors may be discovered which could affect the content, and all legal disclaimers that apply to the journal pertain. 
is the primary psychoactive ingredient in marijuana and it is an agonist at cannabinoid $\mathrm{CB}_{1}$ receptors. Synthetic THC (Marinol ${ }^{\circledR}$ ) is used to treat nausea and vomiting in patients undergoing chemotherapy and anorexia resulting from HIV/AIDS (Mechoulam and Hanus 2001). More recently cannabinoid $\mathrm{CB}_{1}$ receptor antagonists have been examined for their utility in treating obesity (Patel and Pathak, 2007), diabetes (Lebovitz, 2006), metabolic syndrome (Padwal and Majumdar, 2007), for smoking cessation (Siu and Tyndale, 2007), and for modifying the effects of abused drugs (Maldonado et al., 2006).

Non-human species, including rats, self-administer many drugs that are abused by humans, including methamphetamine (Yokel et al., 1973) and the cannabinoid $\mathrm{CB}_{1}$ receptor agonists THC (Takahashi et al., 1979) and WIN 55,212-2 (Fattore et al., 2001). Cannabinoid CB $_{1}$ receptor antagonists decrease the self administration of not only cannabinoid $\mathrm{CB}_{1}$ receptor agonists (Tanda et al., 2000) but also of other drugs, including methamphetamine (Vinklerova et al., 2002). Moreover, cannabinoid $\mathrm{CB}_{1}$ receptor antagonists can prevent reinstatement of responding in animals with a history of opioid (Fattore et al., 2005), ethanol (Cippitelli et al., 2005), or stimulant (e.g., methamphetamine [Anggadiredja et al., 2004a] or cocaine [Xi et al., 2006]) self administration. Thus, it has been suggested that cannabinoid $\mathrm{CB}_{1}$ receptor antagonists might be useful for treating drug abuse and, in particular, relapse (De Vries et al., 2001). To further test the potential utility of cannabinoid $\mathrm{CB}_{1}$ receptor antagonists for treating relapse, the current study examined whether the cannabinoid $\mathrm{CB}_{1}$ receptor antagonist AM251 prevents drug-induced reinstatement of responding in rats that previously self-administered methamphetamine. To confirm that effective i.v. doses of AM251 were used in the reinstatement study, another study examined the ability of i.v. AM251 to block the hypothermic effects of THC.

\section{Methods}

\section{1 Subjects}

Male Sprague Dawley rats (250-300 g, Harlan, Indianapolis, Indiana, USA; n=10, self administration; $n=8$, body temperature) were individually housed in a room maintained under a 12/12h light/dark cycle. For rats in the self administration study, access to food was restricted to $10 \mathrm{~g} /$ day for 3 days before lever press training for food. All experiments, which were conducted in the light cycle, were approved by the Institutional Animal Care and Use Committee of The University of Texas Health Science Center at San Antonio and with the 1996 Guide for the Care and Use of Laboratory Animals (Institute of Laboratory Animal Resources on Life Sciences, National Research Council, National Academy of Sciences).

\subsection{Apparatus}

Self administration experiments were conducted in operant chambers (MED Associates Inc., St. Albans, Vermont, USA) in sound-attenuating cubicles (Coulbourn Instruments, Allentown, Pennsylvania, USA). On one wall of the chamber were two response levers and a food receptacle $(5 \times 5 \mathrm{~cm}$ opening) located $3 \mathrm{~cm}$ above the chamber floor and midway between the levers. A hopper delivered 45-mg food pellets (PJAI-0045, Noyes Precision Pellets; Research Diets Inc., New Brunswick, New Jersey, USA). Stimulus lights located above each lever illuminated the chamber during sessions. Infusion pumps, located on top of the cubicles, delivered drug or vehicle via Tygon tubing (155718; Norton Performance Plastics, Akron, Ohio, USA) through a swivel (504780; Instech Laboratories, Inc., Plymouth Meeting, Pennsylvania, USA) to a 22-gauge Huber point needle (02A25A; Ormco, Corp, Glendora, California, USA). Body temperature was measured by a rectal probe connected to a thermometer (model RET-2, Physitemp, Clifton, New Jersey, USA). 


\subsection{Food Training}

Six of 10 rats in the self administration study were initially trained to press either of two levers for food in daily 60-min sessions; a press of either lever delivered food with a maximum of 50 pellets per session. Based on responding in the first session in which rats received 50 pellets, only the lever on which a rat responded the most was active for the remainder of the study. Responses on the inactive lever were recorded but had no programmed consequence.

Thereafter, when a rat received 50 pellets in two consecutive sessions the response requirement was increased to a fixed ratio 2 .

\subsection{Surgery}

Four of the rats used in the self administration study had received a chronic indwelling catheter to the jugular vein before arrival in the laboratory (i.e., by the vendor) and these rats did not undergo lever press training for food. For the other 6 rats, after lever press training a chronic indwelling catheter was implanted to the jugular vein. Rats were anesthetized with 3\% isoflurane and maintained on 1-2\% isoflurane throughout the procedure. A polyurethane $\mathrm{CBAS}^{\mathrm{TM}}$ 3-French catheter (Instech Solomon, Plymouth Meeting, Pennsylvania, USA) was implanted in the right jugular vein and tunneled s.c. to the midscapular region where it was exteriorized and connected to a venous access port (model ROP, Access Technologies, Skokie, Illinois, USA) that was sutured to a Velcro patch connected to a jacket (model RJ02, Lomir Biomedical Inc, Malone, New York, USA). The 4 rats that were purchased with implanted catheters underwent surgery to connect the catheter to an exteriorized access port. Immediately after surgery and after daily sessions catheters were flushed with $0.1 \mathrm{ml}$ of heparinized-saline $(100 \mathrm{U} / \mathrm{ml})$; sessions started $24 \mathrm{hr}$ after surgery. The 8 rats used in the body temperature study also received a chronic indwelling i.v. catheter, as described above, $3-5$ days before studies.

In the course of these studies catheter patency was occasionally compromised, as indicated by leakage of fluid or resistance in flushing the catheter; confirmation was the failure to achieve rapid sedation after injection via the catheter of $3.0 \mathrm{mg} / \mathrm{kg}$ of methohexital sodium. Once confirmed, the catheter was removed and a second catheter was implanted in the opposite jugular or in a femoral vein; rats were allowed 2 days of recovery.

\subsection{Self Administration/Reinstatement Study}

In daily sessions rats could press a lever to receive i.v. injections of methamphetamine. For rats $(\mathrm{n}=4)$ that did not undergo lever press training for food, initial self administration sessions were a maximum of $120 \mathrm{~min}$ in duration and a maximum of 20 infusions of $0.1 \mathrm{mg} / \mathrm{kg} / \mathrm{infusion}$ of methamphetamine could be received by pressing either lever. When rats received at least 10 infusions in a session, the lever on which the most responses were made was the only active lever for the remainder of the study. When rats received at least 10 infusions of methamphetamine in 4 consecutive sessions, the response requirement was increased to a fixed ratio 2 and the maximum session duration was decreased to $60 \mathrm{~min}$.

For the 6 rats that underwent lever press training for food, self administration sessions were at most 60 min during which rats could receive a maximum of 20 infusions of $0.1 \mathrm{mg} / \mathrm{kg} / \mathrm{infusion}$ of methamphetamine, initially under a continuous reinforcement schedule and eventually (when at least 8 infusions were received in each of 4 consecutive sessions) under a fixed ratio 2 schedule. Methamphetamine self administration was assessed at the beginning of the study and again after methamphetamine priming.

For all 10 rats, when at least 10 infusions of methamphetamine were received in each of 4 consecutive sessions under the fixed ratio 2 schedule, saline was substituted for methamphetamine; extinction was defined as six or fewer saline infusions received in each of 4 consecutive sessions. Next, reinstatement of extinguished responding was assessed with an 
acute i.v. injection of methamphetamine immediately before a session in which i.v. saline was available under the fixed ratio 2 schedule. Doses from 0.01 to 1.78 were studied in order to identify the maximally-effective dose for reinstating lever pressing. Different doses were tested in a nonsystematic order. After these priming tests, self administration with methamphetamine was re-established followed by saline substitution, as described above. Lastly, reinstatement of extinguished responding was assessed in sessions where rats received AM251 (0.032, 0.1 and $0.32 \mathrm{mg} / \mathrm{kg}$ i.v. on different days) in combination with methamphetamine at a dose of 0.1 $\mathrm{mg} / \mathrm{kg}$ that generated the most responding in the first reinstatement study. Different doses of AM251 were tested in a nonsystematic order.

\subsection{Body Temperature Study}

Before the study, animals were handled and body temperature was measured daily for at least 3 days. Subsequently, rats were tested not more than once every 4 days. For each test, rats received 2 injections: $2.0 \mathrm{mg} / \mathrm{kg}$ THC or its vehicle (i.p.) $20 \mathrm{~min}$ before $0.32 \mathrm{mg} / \mathrm{kg}$ AM251 or its vehicle (i.v.). Body temperature was measured immediately before the first injection as well as 30, 60, 90, and $120 \mathrm{~min}$ thereafter. The order of tests was according to a Latin Square. Thereafter, the effects of $2.0 \mathrm{mg} / \mathrm{kg}$ of THC alone were redetermined.

\subsection{Drugs}

Methamphetamine hydrochloride (Sigma-Aldrich Corp, St. Louis, Missouri, USA) was dissolved in 0.9\% saline, and AM251 (Sigma-Aldrich Corp) was dissolved in a 1:1:8 ratio of dimethyl sulfoxide (DMSO, Fischer Chemicals, Fair Lawn, New Jersey, USA), Tween-80 (Fischer Chemicals), and saline, respectively; THC (The Research Technology Branch, National Institute on Drug Abuse, Rockville, Maryland, USA) and midazolam hydrochloride (Bedford Laboratories, Bedford, Ohio, USA) were obtained as solutions and diluted with saline. Methamphetamine and AM251 were administered i.v. and THC was administered i.p. Doses of AM251 were selected based on a previous study (Lan et al., 1999) that used a related cannabinoid $\mathrm{CB}_{1}$ receptor antagonist (SR141716A) after i.v. administration (Pozzi et al., 2003), and based on the assumption that AM251 is approximately two times more potent than SR141716A (Lan et al., 1999). The dose of THC $(2.0 \mathrm{mg} / \mathrm{kg}$, i.p.) in the body temperature study was based on published reports of the hypothermic effects of THC in rats.

\subsection{Data Analyses}

The average $(n=10)$ number of infusions received ( \pm S.E.M.) was recorded for all self administration and reinstatement sessions. For methamphetamine self administration and saline extinction, average data are presented from the last three sessions ( \pm S.E.M.) for each condition. For reinstatement tests, data represent the average ( \pm S.E.M.) of a single session for 10 rats. Body temperature was measured in ${ }^{\circ} \mathrm{C}$ and expressed as an average for 8 rats ( \pm S.E.M.). Self administration data were analyzed with a paired t-test or one-factor (dose) repeatedmeasures ANOVA. Body temperature data were analyzed with two-factor (time, treatment) repeated-measures ANOVA. A significance level of $\mathrm{P}<0.05$ was used throughout.

\subsection{Results}

\subsection{Self Administration/Reinstatement Study}

Stable responding for $0.1 \mathrm{mg} / \mathrm{kg} / \mathrm{infusion}$ of methamphetamine was established (i.e., at least 8 infusions in each of 4 consecutive sessions, fixed ratio 2) after an average of $24.6 \pm 2.7$ sessions $(20.5 \pm 4.0$ sessions in 4 rats that did not undergo lever training for food and $27.3 \pm 3.3$ sessions in 6 rats that were first trained to press levers for food). Over the last three sessions, rats received an average of $9.8 \pm 0.8$ infusions of $0.1 \mathrm{mg} / \mathrm{kg} /$ infusion of methamphetamine (Fig. 1, A); in 
contrast, when saline was substituted for methamphetamine rats received a significantly lower average of $2.0 \pm 0.2$ infusions per session.

After saline extinction, a non-contingent infusion of methamphetamine reinstated responding (for saline) resulting in an inverted-U shaped dose-response curve (Fig. 1, B). Responding for saline after $0.1,0.32$ or $1.0 \mathrm{mg} / \mathrm{kg}$ of methamphetamine was significantly greater than responding for saline in the absence of methamphetamine. Subsequent reestablishment of self administration with $0.1 \mathrm{mg} / \mathrm{kg} /$ infusion of methamphetamine (data not shown) yielded results (i.e., $11.2 \pm 0.7$ infusions per session) that were similar to those obtained at the beginning of the study and substitution of saline for methamphetamine (extinction) again generated very low rates of self administration ( $3.5 \pm 0.5$ infusions per session).

Reinstatement of responding (for saline) by a dose of $0.1 \mathrm{mg} / \mathrm{kg}$ of methamphetamine (Fig. 1, B) was not significantly altered by i.v. administration of AM251 up to a dose of $0.32 \mathrm{mg} / \mathrm{kg}$ (Fig. 1, C). Responding for saline after co-treatment with AM251 and methamphetamine was not different from responding for saline when only methamphetamine was administered before the session.

\subsection{Body Temperature Study}

THC (2.0 mg/kg, i.p.) significantly decreased body temperature 30-120 min after administration ( $\mathrm{P}<0.05$ compared with vehicle; Fig. 2, closed circles and squares). Beginning $60 \mathrm{~min}$ after i.v. administration of $0.32 \mathrm{mg} / \mathrm{kg}$, AM 251 significantly attenuated the hypothermic effect of THC (open and closed squares). There was no significant change in body temperature after the administration AM251 alone. The maximum decrease in body temperature produced by $2.0 \mathrm{mg} / \mathrm{kg}$ of THC $60 \mathrm{~min}$ after administration was not different at the beginning (35.1 \pm $\left.0.4{ }^{\circ} \mathrm{C}\right)$ and end $\left(35.7 \pm 0.2{ }^{\circ} \mathrm{C}\right)$ of these studies.

\subsection{Discussion}

Drugs acting at cannabinoid receptors can modulate the behavioral effects of some drugs of abuse (Landa et al., 2006a,b) and it is becoming clear that endogenous cannabinoids and cannabinoid receptors have an important role in reward mechanisms in brain (Gardner, 2005). In addition to cannabinoid $\mathrm{CB}_{1}$ receptor agonists, which have anti-emetic effects and can stimulate appetite, cannabinoid $\mathrm{CB}_{1}$ receptor antagonists also might have clinical utility for treating obesity, various metabolic disorders, and drug abuse (Maldonado et al., 2006). For example, in non-humans, some cannabinoid $\mathrm{CB}_{1}$ receptor antagonists decrease drug self administration (e.g., Vinklerova et al., 2002) and there is emerging evidence to suggest that these antagonists might also prevent stimulus-elicited reinstatement of responding (i.e., relapse) in animals with a history of drug self administration (Fattore et al., 2007). Still other studies have shown that cannabinoid $\mathrm{CB}_{1}$ receptor antagonists can prevent the development of other behavioral effects (e.g., sensitization) to some (Landa et al., 2006a), but not all (Lesscher et al., 2005), stimulants. The current study examined whether the cannabinoid $\mathrm{CB}_{1}$ receptor antagonist AM251 modifies reinstatement of responding by methamphetamine in rats with a history of responding for methamphetamine.

Methamphetamine maintained reliable self administration as evidenced by a stable, high number of methamphetamine infusions received. When saline was substituted for methamphetamine, responding decreased markedly thereby confirming the positive reinforcing effects of i.v. methamphetamine in this procedure. When rats received an acute infusion of methamphetamine prior to a session in which only saline was available, they responded in a manner that was, for some doses, not different from what was observed when methamphetamine was administered contingently after completion of the fixed ratio 2 . For example, when a unit dose of $0.1 \mathrm{mg} / \mathrm{kg} /$ infusion of methamphetamine was available 
contingent on completion of the fixed ratio, rats received an average of 9.8 drug infusions. When a non-contingent infusion of $0.1 \mathrm{mg} / \mathrm{kg}$ of methamphetamine was administered prior to the session, rats received an average of 11.9 saline infusions. Thus, methamphetamine clearly reinstated responding in rats with a history of methamphetamine self administration. To test whether the cannabinoid $\mathrm{CB}_{1}$ receptor antagonist AM251 modifies reinstatement, different doses of AM251 were administered with a dose of methamphetamine $(0.1 \mathrm{mg} / \mathrm{kg})$ that produced the greatest reinstatement responding. Up to a dose of $0.32 \mathrm{mg} / \mathrm{kg}$, AM251 had no effect on reinstatement by methamphetamine.

Because negative results were obtained with AM251 in the reinstatement study, it was important to determine whether $\mathrm{AM} 251$ was tested at doses with cannabinoid $\mathrm{CB}_{1}$ receptor antagonist activity. It is well established that THC decreases body temperature in rats (Wiley et al., 2007) and in the current study a dose of $2.0 \mathrm{mg} / \mathrm{kg}$ of THC i.p. decreased the average body temperature of rats by more than $2{ }^{\circ} \mathrm{C}$. Importantly, the largest dose of AM251 (0.32 mg/ $\mathrm{kg}$ ), which had no effect in modifying methamphetamine-induced reinstatement, blocked the hypothermic effects of THC. Larger i.v. doses of AM251 could not be studied because they can be lethal in rats (CP France, unpublished observation). Taken together, these data demonstrate that when administered i.v. AM251 is an effective antagonist at cannabinoid $\mathrm{CB}_{1}$ receptors; thus, the failure of AM251 to modify methamphetamine-induced reinstatement was not due to the use of inactive doses of AM251.

Previous studies have shown that cannabinoid $\mathrm{CB}_{1}$ receptor antagonists can decrease self administration of methamphetamine (Vinklerova et al., 2002) as well as methamphetamine(Anggadiredja et al., 2004a) and cocaine (Xi et al., 2006)-induced reinstatement of responding. However, the study on methamphetamine-induced reinstatement used a different antagonist (SR 141716A) from the one used in the current study; and the study that used AM251 used a different stimulant (cocaine) from the one used in the current study. Thus, interactions between cannabinoid $\mathrm{CB}_{1}$ receptor antagonists and stimulants might depend on not only the dose but also the particular antagonist and stimulant studied. While it is possible that reinstatement by other (e.g., non-pharmacologic) stimuli would be sensitive to AM251, as is the case for other drugs (e.g., Anggadiredja et al., 2004b), results from this study fail to support a role for cannabinoid $\mathrm{CB}_{1}$ receptors in reinstatement of responding for methamphetamine.

\section{Acknowledgements}

Thanks to Roxie Jimenez, Olivia Dominguez, Daniel Mojica and Christopher Cruz for their excellent technical assistance.

Supported by DA04195 (JLM), Ewing Halsell Foundations (JLM), and Senior Scientist Award DA17918 (CPF)

\section{References}

Anggadiredja K, Nakamichi M, Hiranita T, Tanaka H, Shoyama Y, Watanabe S, Yamamoto T. Endocannabinoid system modulates relapse to methamphetamine seeking: possible mediation by the arachidonic acid cascade. Neuropsychopharmacology 2004a;29:470-1478.

Anggadiredga K, Sakimura K, Hiranita T, Yamanoto T. Naltrexone attenuates cue- but not drug-induced methamphetamine seeking: a possible mechanism for the dissociation of primary and secondary reward. Brain Res 2004b;24:272-276.

Bray GA. Use and abuse of appetite-suppressant drugs in the treatment of obesity. Ann Intern Med 1993;119:707-713. [PubMed: 8363202]

Cippitelli A, Bilbao A, Hansson AC, del Arco I, Sommer W, Heilig M, Massi M, Bermudez-Silva FJ, Navarro M, Ciccocioppo R, de Fonseca FR. The European TARGALC Consortium. Cannabinoid $\mathrm{CB}_{1}$ receptor antagonism reduced conditioned reinstatement of ethanol-seeking behavior in rats. Eur J Neurosci 2005;21:2243-2251. [PubMed: 15869521] 
De Vries TJ, Shaham Y, Homberg JR, Crombag H, Schuurman K, Dieben J, Vanderschuren LJ, Schoffelmeer AN. A cannabinoid mechanism in relapse to cocaine seeking. Nat Med 2001;7:11511154. [PubMed: 11590440]

Fattore L, Cossu G, Martellotta CM, Fratta W. Intravenous self-administration of the cannabinoid CB1 receptor agonist WIN 55,212-2 in rats. Psychopharmacology 2001;156:410-416. [PubMed: 11498718]

Fattore L, Spano S, Cossu G, Deiana S, Fadda P, Fratta W. Cannabinoid CB 1 antagonist SR 141716A attenuates reinstatement of heroin self-administration in heroin-abstinent rats. Neuropharmacology 2005;48:1097-1104. [PubMed: 15910886]

Fattore L, Spano JS, Deiana S, Melis V, Cossu G, Fadda P, Fratta W. An endocannabinoids mechanism in relapse to drug seeking: a review of animal studies and clinical perspectives. Brain Res Rev 2007;53:1-16. [PubMed: 16839608]

Gardner EL. Endocannabinoid signaling system and brain reward: emphasis on dopamine. Pharmacol Biochem Behav 2005;81:263-284. [PubMed: 15936806]

Greenhill LL. The science of stimulant abuse. Pediatr Ann 2006;35:552-556. [PubMed: 16986449]

Kroutil LA, Van Brunt DL, Herman-Stahl MA, Heller DC, Bray RM, Penne MA. Nonmedical use of prescription stimulants in the United States. Drug Alcohol Depend 2006;84:135-143. [PubMed: 16480836]

Landa L, Slais K, Sulcova A. Impact of cannabinoid receptor ligands on behavioural sensitization to antiaggressive methamphetamine effects in the model of mouse agonistic behaviour. Neuro Endocrinol Lett 2006a;27:703-710. [PubMed: 17187025]

Landa L, Sulcova A, Slais K. Involvement of cannabinoid CB1 and CB2 receptor activity of behavioral sensitization to methamphetamine effects in mice. Neuro Endocrinol Lett 2006b;27:63-69. [PubMed: 16648795]

Lesscher HM, Hoogveld E, Burbach JP, van Ree JM, Gerrts MA. Endogenous cannabinoids are not involved in cocaine reinforcement and development of cocaine-induced behavioural sensitization. Eur Neuropsychopharmacol 2005;15:31-37. [PubMed: 15572271]

Lan R, Liu Q, Fan P, Lin S, Fernando SR, McCallion D, Pertwee R, Makriyannis A. Structure-activity relationships of pyrazole derivatives as cannabinoid receptor antagonists. J Med Chem 1999;42:769776. [PubMed: 10052983]

Maldonado R, Valverde O, Berrendero F. Involvement of the endocannabinoids system in drug addiction. Trends Neurosci 2006;29:225-232. [PubMed: 16483675]

Mechoulam R, Hanus L. The cannabinoids: an overview. Therapeutic implications in vomiting and nausea after cancer chemotherapy, in appetite promotion, in multiple sclerosis and in neuroprotection. Pain Res Manag 2001;6:67-73. [PubMed: 11854768]

Pozzi O, Misiano P, Clark GD, Visentin L. Antagonism between the anti-inflammatory activity of the cannabinoid WIN 55212-2 and SR 141716A. Pharmacology 2003;69:158-163. [PubMed: 14512703]

Substance Abuse and Mental Health Services Administration (SAMHSA). Office of Applied Studies, NSDUH Series H-28, DHHS Publication No. SMA 05-4062. Rockville, MD: 2005. Results from the 2004 National Survey on Drug Abuse: National Findings.

Takahashi RN, Singer G. Self-administration of delta 9-tetrahydrocannabinol by rats. Pharmacol Biochem Behav 1979;11:737-740. [PubMed: 231789]

Tanda G, Munzar P, Goldberg SR. Self-administration behavior is maintained by the psychoactive ingredient of marijuana in squirrel monkeys. Nat Neurosci 2000;3:1073-1074. [PubMed: 11036260]

Trang T, Sutak M, Jhamandas K. Involvement of cannabinoid $\left(\mathrm{CB}_{1}\right)$-receptors in the development and maintenance of opioid tolerance. Neurosci. 200710.1016/j.neuroscience.2007.02.031

Vinklerova J, Novakova J, Sulcova A. Inhibition of methamphetamine self-administration in rats by cannabinoid receptor antagonist AM 251. J Psychopharmacol 2002;18:139-143. [PubMed: 12095072]

Wiley JL, O'Connell MM, Tokarz ME, Wright MJ Jr. Pharmacological effects of acute and repeated administration of $\Delta^{9}$-tetrahydrocannabinol in adolescent and adult rats. J Pharmacol Exp Ther 2007;320:1097-1105. [PubMed: 17172531] 
Xi ZX, Gilbert JG, Peng XQ, Pak AC, Li X, Gardner EL. Cannabinoid CB 1 receptor antagonist AM251 inhibits cocaine-primed relapse in rats: role of glutamate in the nucleus accumbens. J Neurosci 2006;26:8531-8536. [PubMed: 16914679]

Yamamoto T, Anggadiredja K, Hiranita T. New perspectives in the studies on endocannabinoid and cannabis: a role for the endocannabinoid-arachidonic acid pathway in drug reward and long-lasting relapse to drug taking. J Pharmacol Sci 2004;96:383-388.

Yan Y, Nitta A, Mizoguchi H, Yamada K, Nabeshima T. Relapse of methamphetamine-seeking behavior in C57BL/6J mice demonstrated by a reinstatement procedure involving intravenous selfadministration. Behav Brain Res 2006;15:137-143. [PubMed: 16413064]

Yokel RA, Pickens R. Self-administration of optical isomers of amphetamine and methylamphetamine by rats. J Pharmacol Exp Therap 1973;187:27-33. [PubMed: 4795731] 
(A)

\section{self-administration of methamphetamine (M) and saline (S) \\ (number of infusions; mean \pm S.E.M.)}

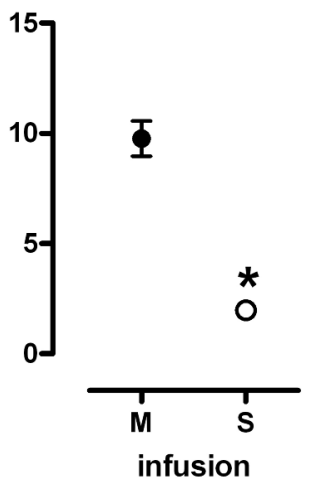

(B)

self-administration of saline
after non-contingent
methamphetamine

(number of infusions; mean \pm S.E.M.)

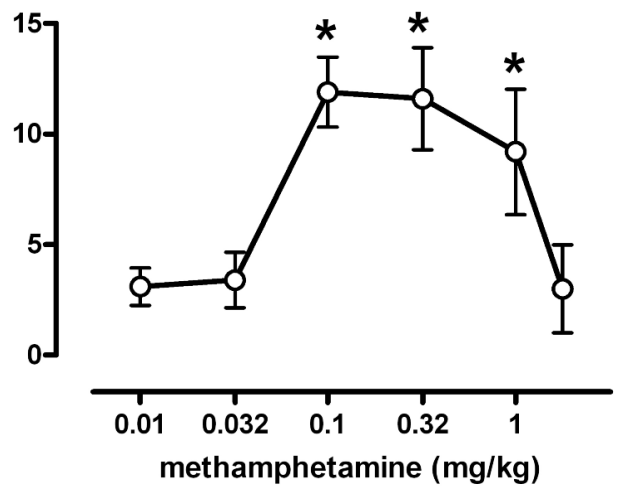

(C)

self-administration of saline after non-contingent methamphetamine $(0.1 \mathrm{mg} / \mathrm{kg})$ together with AM251

(number of infusions;
mean \pm S.E.M.)

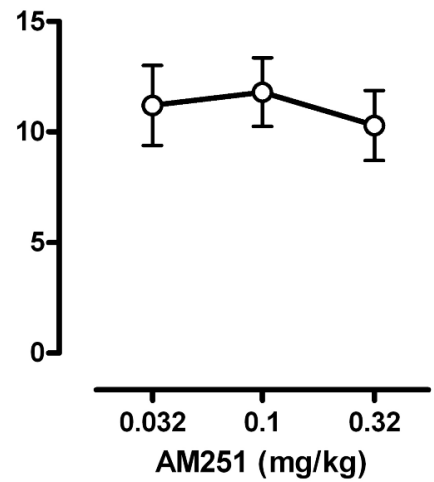

Fig. 1.

A: i.v. self-administration of $0.1 \mathrm{mg} / \mathrm{kg} /$ infusion methamphetamine (M) and saline (S) in 10 rats responding under an fixed ratio 2 schedule $(* \mathrm{P}<0.05$ versus $\mathrm{M})$. B: responding for saline in sessions immediately preceded by i.v. administration of methamphetamine $(* \mathrm{P}<0.05$ versus $\mathrm{S}$ in left panel). C: responding for saline in sessions immediately preceded by $0.1 \mathrm{mg} / \mathrm{kg}$ of methamphetamine and AM251. Ordinate: average number of infusions received for 10 rats. Abscissae: B and C, dose in $\mathrm{mg} / \mathrm{kg}$. 


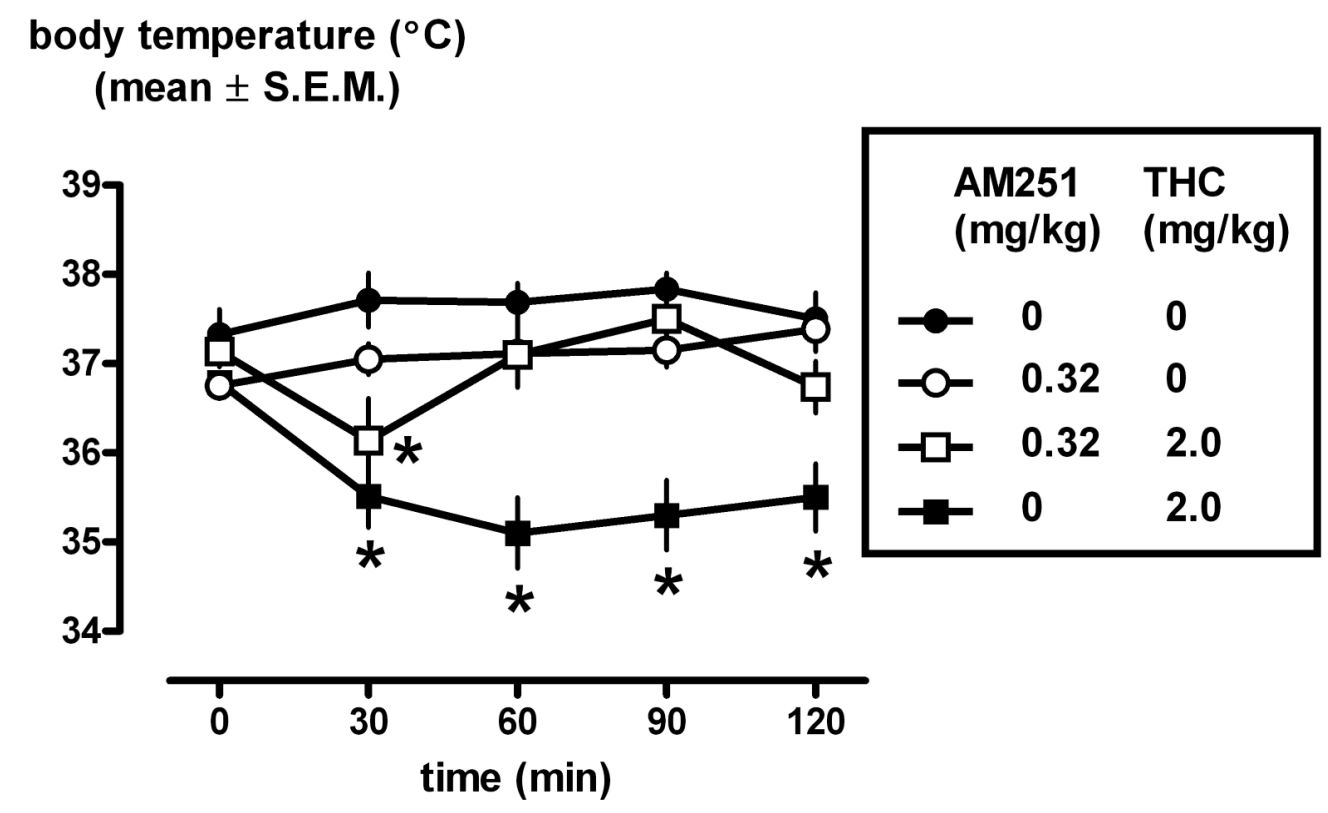

Fig. 2.

Average body temperature $\left({ }^{\circ} \mathrm{C}\right)$ for 8 rats before $(0)$ and for $120 \mathrm{~min}$ after administration of $0.32 \mathrm{mg} / \mathrm{kg}$ AM251 and $2.0 \mathrm{mg} / \mathrm{kg}$ THC alone or together. 